\title{
FELIPE II, LA CIENCIA Y EL NUEVO MUNDO
}

POR

\author{
RAQUEL ÁLVAREZ PELÁEZ
}

Centro de Estudios Históricos, CSIC

\begin{abstract}
A lo largo del siglo XVI la ciencia española alcanzó un gran desarrollo, especialmente en algunos campos como el de la navegación, la minería, la historia natural, etc. El descubrimiento del Nuevo Mundo fue factor esencial en el impulso de ese desarrollo científico, que favorecido y estimulado por Felipe II, fue también dificultado durante su reinado, en gran medida debido a los graves problemas religiosos, económicos y políticos que se plantearon en esos años.
\end{abstract}

El desarrollo de la ciencia en el siglo XVI estuvo ligado, en España, además de a los procesos comunes con el resto de Europa - el despertar humanista y renacentista-, al descubrimiento de América. Surgieron así importantes cambios en las técnicas de navegación, cartografía, medición de latitudes, construcción de barcos, y en la medicina, las ciencias naturales, la minería, etc., aspectos del conocimiento muy ligados al encuentro de una nueva naturaleza, unas floras y faunas que debían ser descritas y comparadas con las especies más conocidas. Durante el reinado de Felipe II este proceso tuvo estímulos, como el envío de Francisco Hernández a Nueva España, pero también obstáculos que se manifestaron en censura, índices de libros y prohibición de trasladarse al extranjero.

En los siglos XV y XVI hubo cambios profundamente importantes en el desarrollo del conocimiento. Estos cambios y nuevas actitudes se han llamado, básicamente, Humanismo y Renacimiento $^{1}$, recuperación de los antiguos textos griegos y latinos, recupera-

1 Eugenio Garín, Medioevo y Renacimiento, Madrid, Taurus Ediciones, 1981; Ágnes Heller, El Hombre del Renacimiento, Barcelona, Ediciones Península, 1980; Mauricio 
ción de la antigua forma de preguntarse sobre el hombre y la naturaleza y sus relaciones, afirmación de la posibilidad de conocimiento por medio del estudio y buscando métodos y formas de organizar la forma de conocer. En el siglo XVI español se vivió, con sus características, como en el resto de los países europeos, esta afirmación del hombre y la naturaleza, y un humanismo que recuperaba textos traduciéndolos de sus idiomas originales, griego y latín, comparándolos con su traslado hecho por los grandes pensadores musulmanes o por los grandes pensadores cristianos. Por otra parte, se comenzó a buscar en la realidad lo que los clásicos decían -Plinio o Galeno, Aristóteles o Euclides - y a contrastar ese conocimiento directo y personal con el de los grandes textos.

La primera mitad del siglo XVI español estuvo caracterizada, bajo el reinado del emperador Carlos, por ese humanismo que se manifestó en la aparición de grandes pensadores, como Juan Luis Vives $^{2}$, que valoraron la importancia del conocimiento teórico y práctico, así como por la aparición de universidades como la de Alcalá de Henares, fundada por Cisneros e impulsada por Elio Antonio de Nebrija ${ }^{3}$ para justamente promover y formar profesionales en esa línea humanística. Allí estudiaron muchos de los médicos, por ejemplo, que impulsaron la ciencia moderna en la segunda mitad del siglo XVI, durante el reinado de Felipe II. La ciencia, teórica y prácti-

\footnotetext{
JALÓN, La plaza de las ciencias, Salamanca, Junta de Castilla y León, 1991; J.A. MARAVALL, Antiguos y modernos, Madrid, Sociedad de Estudios y Publicaciones, 1966.

2 Juan Luis VIVES reflexionó sobre los problemas de la educación e insistió en la necesidad de un conocimiento directo y práctico de las cosas de la naturaleza. Recomendaba el estudio de la cosmografía y la historia natural, de la filosofía natural, la medicina y la agricultura. Buscaba, de alguna manera, la relación de la práctica y la teoría.

3 Elio Antonio de NEBRIJA, consciente de la importancia de la lengua y del vocabulario, se interesó por las matemáticas, la astronomía, la geografía y la historia natural, ejerciendo verdadera influencia tanto desde el punto de vista humanístico como científico, tan íntimamente ligados en esos momentos. El proceso de la penetración humanística en las ciencias fue relativamente lento, y tuvo que encontrar quien lo respaldase y luchar contra quienes se oponían a todo cambio en las lecturas, interpretaciones y nuevas actitudes en el conocer. Eso hizo Nebrija en las materias antes señaladas, y de ahí su importancia para la historia de la ciencia, contribuyendo, en su lucha por el uso de los textos clásicos y el establecimiento de un lenguaje propio, al avance del saber en la España del XVI. En historia natural, por ejemplo, contribuyó al establecimiento de la corriente humanística haciendo editar, en Alcalá, en 1518, la versión latina de la Materia Médica de Dioscórides realizada por Jean de Ruel. Pero además, Nebrija le añade algo fundamental, la correspondencia de los nombres griegos y latinos de las plantas en la lengua vulgar: un Lexicon illarum vocum quae ad medicamentariam artem pertinent.
}

R. I., $1999, \mathrm{n}^{\circ} 215$ 
ca, comenzó a surgir de la actividad de muchos pensadores españoles, aunque muchos otros se mantuvieran aferrados a la seguridad de las antiguas concepciones. Se publicaron obras originales de matemáticas, técnicas de navegación, cartografía, geografía, historia natural, medicina, albeitería ${ }^{4}$ y un largo etcétera.

La segunda mitad del siglo XVI — casi coincidente con el reinado de Felipe II- se caracterizó pues, por el desarrollo de esa incipiente ciencia moderna, pero también por el comienzo de la aplicación del radicalismo religioso impulsado por el Concilio de Trento, que sólo creó dificultades al desarrollo científico, aunque también hubo razones políticas, económicas y sociales que incidieron en las dificultades del desarrollo científico. Sin embargo, como veremos, fue un tiempo floreciente para la literatura científica, para inventos y búsquedas de soluciones para todo tipo de problemas, desde la minería y la forma de extraer los metales, hasta la navegación y la búsqueda de relojes que permitieran medir el arco de meridiano y determinar en geografía, no sólo la latitud, sino la longitud con exactitud. La historia natural alcanzó también unos especiales conocimientos y surgieron museos de curiosidades como el que poseía el noble Gonzalo Argote de Molina en Sevilla, en el que se encontraba el armadillo que cita el médico y comerciante en productos americanos Nicolás Monardes en su libro sobre las drogas americanas. Dice Monardes al pie de una representación del animal:

«Este animal saqué de otro natural, que está en el Museo de Gonçalo de Molina, un caballero de esta ciudad, en el cual hay mucha cantidad de libros de varia lección, y muchos géneros de animales y aves, y otras cosas curiosas, traídas así de la India Oriental como Occidental, y de otras partes del mundo, y gran copia de monedas y piedras antiguas, y diferencias de armas, que con gran curiosidad y con generoso ánimo ha allegado»5.

4 La obra de conjunto más importante sobre este tema sigue siendo la de Cesáreo Sanz Egaña, Historia de la Veterinaria Española. Albeitería - Mariscalería - Veterinaria, Madrid, Espasa-Calpe, 1941.

5 Nicolás MonARDES, Primera, Segunda y Tercera partes de la Historia Medicinal: de las cosas que se traen de nuestras Indias Occidentales, que sirven en Medicina, Sevilla, Padilla Libros, 1988. Edición facsimilar de la de Sevilla, Alonso Escrivano, 1574. En el folio 81 aparece una representación del armadillo. 
Y surgieron y se desarrollaron verdaderos jardines botánicos, con cierta relación todavía con la medicina, pero propiciada su independencia, su orientación, a un conocimiento de la flora por sí misma gracias al interés despertado por el exotismo americano. Felipe II tenía sus jardines botánicos, plantaciones especiales en Sevilla y en Aranjuez, y abastecía su botica y sus destiladores del Escorial, en la que sus alquimistas realizaban experiencias con productos, y se hacían desde destilados de rosas hasta medicamentos especiales. Y, también en Sevilla, el médico Simón de Tovar ${ }^{6}$ de origen portugués, gran estudioso de la medicina y la farmacopea, tenía su Jardín Botánico en la zona de los Caños de Carmona, un jardín con orientación científica moderna. Tovar, a quien visitó el naturalista Carolus Clusius - o Charles de l'Ecluse - cuando recorrió España con uno de los banqueros Fugger, publicaba catálogos de las plantas de su jardín e intercambiaba incluso semillas con el estudioso francés antes citado y se mantenía en contacto con el ambiente científico de los Países Bajos a través de su amigo Benito Arias Montano. Arias Montano también se mostraba muy interesado por los productos botánicos, e incluso por otros de origen animal con propiedades, tradicionalmente, curativas, las piedras bezoar, en este caso americanas. Lo mismo sucedía con el gran cosmógrafo Rodrigo Zamorano, otro de los amigos de Arias Montano y Simón de Tovar ${ }^{7}$. Muerto Tovar, Rodrigo Zamo-

\footnotetext{
6 Simón de Tovar es una figura aún poco estudiada A pesar del interés que presenta, así como todo el resto del núcleo de estudiosos sevillanos. Debemos recordar que Sevilla era una ciudad de más de 100.000 habitantes, en conexión directa con el Nuevo Mundo, pero también con el resto de Europa, a la que llegaban los metales preciosos y todos los productos americanos que servían a la medicina, la alimentación, etc.; era la gran ciudad del comercio. Tovar, nacido en Portugal en fecha incierta, murió en Sevilla en 1596, habiendo publicado tres obras, una sobre la preparación de los compuestos farmacéuticos, otra sobre el control de las boticas sevillanas, estableciendo pesos y medidas, y una tercera sobre el uso de la ballestilla para medir la altura de la estrella Polar y determinar la latitud, en comparación con la utilidad del astrolabio. Un trabajo para la Casa de Contratación. Esta capacidad para tratar temas tan diversos es muy típica de los estudiosos de la época, personajes que cuando se dedicaban al estudio solían saber prácticamente de todo. Hay muy interesante información sobre Simón de Tovar, su familia, sus negocios, su testamento, etc. en el libro de Juan GIL, Arias Montano en su entorno. [Bienes y Herederos], Mérida, Editora Regional de Extremadura, 1998.

7 Dice Juan Gil, [6], p. 89, que en la segunda mitad del siglo XVI comenzó el gusto por lo exótico, y agrega: «Mientras que las paredes del Alcázar sevillano se cubrían de azulejos representando a los indios del Nuevo Mundo, los particulares coleccionaban a porfía piezas exóticas de los cuatro continentes: el alemán Jacques Reitiman, que murió en Sevilla, tenía en su poder dos colmillos, al parecer de elefante; el cosmógrafo R. Zamorano,
} 
rano - cosmógrafo y matemático de Medina de Rioseco, trasladado a la Casa de Contratación y muerto en Sevilla en 1620 - intentó que el ayuntamiento de Sevilla conservara el jardín botánico de su amigo explicando que sería muy barato mantenerlo y que era lamentable que se perdiera. No sabemos qué sucedió, pues, no hemos vuelto a encontrar referencias sobre este jardín.

En los dos reinados - en realidad en los tres, pues el de los reyes Isabel de Castilla y Fernando de Aragón fue esencial en este aspecto- hubo un factor fundamental para el impulso del conocimiento de la naturaleza, el descubrimiento de América, de las Indias Occidentales. Tal fue el impacto, que una cardenal italiano, Egidio da Viterbo, elogia al Papa del descubrimiento, Julio II, de forma fervorosa diciendo:

«En Orvieto, restaurada por tu sabiduría, me transporto a aquel día de los cónsules, anuncio un acontecimiento de entre todos el mayor, muestro la felicidad de la fe bajo tu pontificado, hago convocar al pueblo, salgo al púlpito y al gentío atónito con las palabras que encuentro, le muestro la grandeza de los beneficios reunidos bajo mi pontífice Julio: Explico que aquello que durante cerca de seis mil años había permanecido escondido, aquello que estaba donde los antípodas, los hombres que viven bajo otro cielo, las islas ignotas, un mundo desconocido, la tierra, el océano del que se había dudado, todo había sido descubierto, conocido, explorado, y sólo en la época de mi príncipe. No hubo hasta ahora ningún príncipe para el cual se dejasen descubrir los lugares de desconocidas tierras. Eligieron precisamente a Julio, pontífice máximo, no sólo para descubrirse a su inteligencia, sino también para obedecer a su autoridad y a su imperio. He mostrado que Ptolomeo sólo había descrito la mitad del mundo, y que el pontífice Julio lo ha descubierto todo ${ }^{8} »$.

El comienzo de la navegación atlántica, que iniciaron e impulsaron los portugueses, fue el primer paso de la expansión del mundo conocido. Los mares y las tierras comenzaron a ampliarse por el mar, pero las tierras a las que arribaban eran todavía parte de un

como examinador que era de los maestres de la carrera de las Indias, tenía «las paredes de los portales de su casa todos llenos de estas conchas, peces y animales muy de ver"» según carta del médico Juan de Castañeda a Clusio, del 20 de octubre de 1600.

8 Egidio da Viterbo a Julio II, el 18 de agosto de 1508, según G. SigNORELLI, Il cardinale Egidio da Viterbo, agostiniano, umanista e riformatore, Florencia, 1929, pp. 235-236, citado a su vez en E. Garín, El Renacimiento italiano, Barcelona, Ed. Ariel, 1986, pp. 64-65. 
mundo, si no conocido totalmente, sí concebido como existente. Pero el cruce del Atlántico en busca de esas mismas tierras descubiertas por los portugueses hizo que el descubrimiento de Colón aportara una nueva imagen del mundo, no sólo por la definitiva aseveración de la esfericidad de la tierra, sino por el descubrimiento — desde el punto de vista europeo, evidentemente- de la existencia de una nueva naturaleza y unos hombres nuevos, aunque semejantes en todo, -lo que quería decir no monstruosos, tenían sus cabezas y miembros en el mismo sitio que ellos, etc- pero diferentes a lo conocido. Eran decubrimientos cada vez más sorprendentes: al comienzo fueron unas islas pobladas por gente salvaje, sin «policía», sin organización social aparente, o por lo menos muy pobre, después aparecieron también pobladores en la Tierra Firme, incluso en zonas no concebibles como pobladas, y después fue el encuentro de una civilización rica y cultivada, como la azteca, con conocimientos sobre medicina e historia natural, sobre astrología y astronomía; con palacios y mercados, con grandes templos, jardines botánicos y zoológicos y una organización social perfectamente estructurada. Hasta el punto de que los Reyes Católicos indicaron a Hernán Cortés que no rompiera esa estructura, que no hiciera repartimientos, sino que, manteniendo esa organización, se dedicara a cobrar los tributos en lugar de los caciques propios. Isabel y Fernando eran conscientes del fracaso que había sido la forma de hacer en las islas del Caribe, y no querían repetir esa situación. Pero Cortés no podía contener la ambición de sus hombres, ni la suya propia, y tenía que pagarles con tierras y con indígenas a su servicio.

El descubrimiento provocó gran cantidad de escritos, de descripciones y relatos en los que casi en todos los casos, se incluían detalles sobre la naturaleza americana. Su vegetación, su fauna, sus características geográficas; sus riquezas vegetales, útiles para la medicina o para la alimentación como patatas, pimientos, tomates, maíz, calabazas, frijoles, etc. etc. O productos tintóreos como la grana cochinilla o el palo campeche, medicinas como el guayacán, el bálsamo, la zarzaparrilla. Productos especialmente sorprendentes como el tabaco - siempre polémico, defendido por unos como medicinal, atacado por otros como perjudicial - o como el «xocolatl» el chocolate que se difundió por Europa, y también denostado por unos y alabado por otros. Y animales sorprendentes —el tapir, el armadillo, el mapache, el manatí- o semejantes, aunque diferentes a los nues-

R. I., $1999, \mathrm{n}^{\circ} 215$ 
tros o a los conocidos, como el llamado león americano, el puma, o el tigre americano o jaguar. Las primeras crónicas y relatos, e incluso las especies llevadas por Colón y otros conquistadores y viajeros, como los papagayos, la iguana o el armadillo, despertaron rápidamente el interés de quienes comenzaban a buscar nuevas especies vegetales y animales en Europa. Se abrió todo un enorme mundo nuevo de riqueza geográfica, geológica, mineral, vegetal, animal y humana. Fue un estímulo para buscar los mejores métodos de navegación, construir las cartas geográficas más perfectas y exactas, fabricar los barcos más adecuados para el nuevo mar, que después se extendió al cruce del Mar del Sur, del Océano Pacífico para llegar desde México a las Molucas ${ }^{9}$. Y había que encontrar las formas más económicas y sencillas para extraer el oro y la plata, para valorar y medir los productos, para buscarlos y transportarlos. También era necesario conocer, lo más exactamente posible, la localización de cada zona, de cada grupo de población, de cada pueblo o villa, de cada río, de las costas y montañas, de los pasos y de los puertos, de los vientos y las mareas. Con esto quiero decir que el estímulo creado por el descubrimiento de América fue, para la ciencia europea, esencial. Y digo para la ciencia europea porque, aunque fue el Imperio Español el receptor directo de este estímulo, las noticias se difundieron con rapidez por toda Europa. En parte, porque el Imperio comprendía gran parte de Europa, y partes muy significativas desde el punto de vista de la ciencia y el conocimiento, como Flandes, el Milanesado o el reino de Nápoles, y en parte por la difusión de muchos de los escritos de los españoles por personajes como Pedro Martir de Anglería ${ }^{10}$ desde los primeros tiempos del descubrimiento,

9 Sobre la fabricación de navíos puede consultarse, de M. ${ }^{a}$ Isabel VICENTE MAROTO, Diálogo entre un Viscaíno y un Montañés sobre la fábrica de navíos, Salamanca, Ediciones de la Unversidad de Salamanca, 1998, en el que de encontrará, además de un texto inédicto, una excelente bibilografía sobre el tema.

10 Pedro Mártir de Anglería había nacido en el Milanesado, a orillas del lago Mayor, entre 1455 y 1459 . Noble y humanista viene a España bajo la protección del Conde de Tendilla y se sitúa en la Corte. Escribió una serie de epístolas o relatos sobre el descubrimiento y conquista del llamado por él mismo Orbe Novo, Nuevo Mundo, a lo largo de treinta años a partir de 1493. Pero él nunca pisó el nuevo continente, aunque se informó muy detalladamente de todo lo concerniente a él, a todos los acontecimientos y novedades que fueron produciéndose en ese amplio período. Su obra se tituló Decadas De Orbe Novo, y se publicó a partir de 1511, siendo la primera edición completa la de 1530, cuatro años después de su muerte. Hoy en día existe una nueva edición: Pedro MÁRTIR DE ANGLERÍA, Décadas del Nuevo Mundo, Madrid, Ediciones Polifemo, 1989. 
utilizando relatos orales y escritos de viajeros y conquistadores, y escribiendo a sus importantes amigos italianos. Mártir recibió en su casa a un número asombroso de personalidades de la época, desde Cristóbal Colón y su hijo Diego, Fray Ramón Pané, Gonzalo Fernádez de Oviedo y diversos navegantes y conquistadores como Pedrarias Dávila, hasta Sebastian Cabot, el piloto inglés. Además, se traducían las obras españolas total o parcialmente, había correspondencia entre científicos, comerciantes -y personajes que a menudo eran ambas cosas, como Fernández de Oviedo o Nicolás Monardes- embajadores, políticos, frailes y múltiples interesados en tantas y tan curiosas novedades. También había viajeros que acompañaban a los españoles, desde el segundo viaje de Colón en adelante ${ }^{11}, \mathrm{y}$ las naciones europeas, empeñadas también en viajes y exploraciones, comenzarán a llegar a territorios americanos, no sólo en expediciones comerciales y de piratería, como las de los Hawkins, John y William y Francis Drake ${ }^{12}$, o políticas, como las francesas hacia el Brasil o Florida, y la búsqueda del establecimiento de colonias, como hicieron Jean de Léry y su compañero hugonote René Laudonnière ${ }^{13}$ y la que intentó organizar Sir Walter Ralegh en Roanoke, Virginia, quien además llevaba a grandes estudiosos como el matemático Thomas Harriot y el naturalista y magnífico pintor John White ${ }^{14}$. Pero los libros de navegación españoles eran los utilizados por quienes querían aprender a navegar transoceánicamente y no sólo haciendo cabotaje, como los ingleses antes citados. El segundo

11 En el segundo viaje, acompañaban a Colón, además del médico sevillano Diego Álvarez Chanca, los italianos Guillermo Coma, Simón Verde, mercader florentino y el culto y crítico saonés Miguel de Cúneo, todos ellos autores de epístolas en las que se habla de la naturaleza. Cúneo describe especies vegetales sin darles nombres, y una gran cantidad de especies marinas, incluso el manatí.

12 Richard HaKLUYT, Voyages and Discoveries. The Principal Navigations, Voyages, Traffiques and Discoveries of the English Nation., Middlesex, Penguin Classics, 1987: «The voyage made by Mr John Hawkins to the coast of Guinea and the Indies of Nova Hispania, 1564» pp. 105-116 (1564); «The famous voyage of Sir Francis Drake into the South Sea, and there hence about the whole globe of the earth, begun in the year of our Lord, 1577», pp. 171-188.

13 André THEVET, Singularités de la France Antarctique, publicado en 1557, es una descripción de su estancia en Brasil en la que habla de la fauna, la flora y las costumbres de los «cannibales». Jean de LÉRY publicó Histoire d'un voyage fait en la terre du Brésil en 1578.

14 Puede consultarse, de Kenneth R. ANDREWS, Trade, plunder and settlement. maritime enterprise and the genesis of the Britsh Empire, 1480-1630, Cambridge, Cambridge University Press, 1984,y el magnífico libro de Teodoro de BRY, América. De Bry, 1590-1634, Edición de G. Sievernich, Prólogo de John H. Elliott, Madrid, Ediciones Siruela, 1992. 
declaraba que utilizaba el libro de navegación de Pedro de Medina y su Regimiento de navegación, para sus incursiones americanas. La obra de Martín Cortés, Breve compendio de la Sphera y de la arte de navegar con nuevos instrumentos y reglas exemplificado con muy subtiles demonstraciones, ligeramente posterior en el tiempo a la de Medina, suscitó tanto interés que un grupo de comerciantes ingleses pagó su traducción y publicación como The Art of Navigation ${ }^{15}$. Y los navegantes ingleses se trasladaban a la Casa de Contratación de Sevilla, primera gran escuela de navegantes y de cartógrafos, para aprender las nuevas técnicas ${ }^{16}$. Sin embargo, lo cierto es que tales inicios no dieron, por fin, lugar a un desarrollo continuado de la ciencia, y muchas de las naciones que comenzaron observando y participando de la actividad técnica y científica española fueron quienes tuvieron estudiosos y organizaciones académicas que llevaron adelante los nuevos conocimientos en todos los terrenos. Durante el reinado de Felipe II se promocionaron actividades científicas, pero también se fue, poco a poco, limitando esas actividades, y no solamente por los problemas de control de la información sobre las Indias Occidentales -que comenzó en los años cincuenta del siglo XVI, practicamente con la ascensión al trono de Felipe ${ }^{17}$ — sino por la misma evolución económica y social, con grandes crisis económicas, en gran medida creadas por las guerras desmedidas de la política de Felipe II, y con grandes cambios demográficos $\mathrm{y}$, posiblemente, la destrucción de tejido ciudadano y de grupos medios de población.

15 Pedro de Medina, Arte de navegar en que se contienen todas las reglas, Declaraciones, Secretos y Avisos que a la buena navegación son necessarios, y se deven saber, Valladolid, 1545, obra que se tradujo al francés, holandés, italiano e inglés. Publicó Medina otras obras, tanto de navegación y cartografía como de muchos otros temas. El libro de Martín Cortés se publicó en Sevilla en 1551, se reimprimió en 1556 y se editó ocho veces en inglés entre 1561 y 1630.

16 Sigue siendo impresindible el libro de José Pulido Rubio, El Piloto Mayor. Pilotos Mayores, Cetedráticos de Cosmografía y Cosmógrafos de la Casa de Contratación, Sevilla, EEH-CSIC, 1950.

17 El primer índice de obras censuradas por la Inquisición, estando al frente de ella Fernando de Valdés, se publicó en 1551, pero en 1559 se publica el definitivo de este Gran Inquisidor. José PARDO TOMÁS, Ciencia y Censura. La Inquisición Española y los libros científicos en los siglos XVI y XVII, Madrid, CSIC, 1991, nos señala que entre esas fechas puede verse «el miedo al peligro luterano y sus posibilidades de expansión en el seno de la monarquía hispánica» (p. 50). Miedo que se incrementa con el descubrimiento de los focos lutaranos de Valladolid y Sevilla entre 1557 y 1559. 
Como hemos señalado, pues, los desarrollos científicos españoles más llamativos durante el reinado de Felipe II se produjeron en los terrenos de la cosmografía, cartografía y navegación, en la metalurgia y en la medicina y en las ciencias naturales en general, siempre muy ligadas al arte de cuarar. Pero que, de alguna manera, comenzaban a alcanzar una cierta independencia y entidad propia, impulsada en gran medida por el descubrimiento del Nuevo Mundo, como veremos al referirnos particularmente a este aspecto del conocimiento.

Hemos hablado de la importancia que adquirió, desde que los portugueses abrieron las rutas oceánicas, el arte de navegar. Aunque se conocía la brújula, y se utilizaba en la navegación mediterránea y de los mares de Asia, los mapas que se utilizaban, los «portulanos», señalaban encrucijadas de rumbos en reláción con los puntos cardinales. De esas «cartas de compás» se pasó a mapas en que se determinaban alturas de los astros que permitían determinar de alguna manera la distancia a la línea Equinoccial o Ecuador, la latitud. Esto exigía, al mismo tiempo, el desarrollo y difusión de buenas tablas astronómicas con indicaciones de la posición de la estrella Polar, o, para el hemisferio sur, la Cruz del Sur y la declinación del sol. Las tablas de declinación solar del Almanach de Abraham Zacuto fueron utilizadas para la preparación de manuales que permitían calcular las latitudes. Todas estas ténicas, la creación de mapas y cartas de navegación utilizando las latitudes, y cuando era posible, en tierra, las longitudes, se fueron desarrollando en la Casa de Contratación de Sevilla, fundada en 1503 como centro de control de la corona, en la que se crea en 1523 el puesto de cosmógrafo Mayor del Rey y en 1552 la cátedra de navegación y Cosmografía. Y mucha de la temática pasará a integrarse en la Academia de Matemáticas de Madrid, desgraciadamente de escaso desarrollo, fundada por Felipe $\mathrm{II}^{18}$. Otro aspecto decisivo para la navegación fue la transformación de las naves que culminó con el desarrollo de carabelas y galeones. Para todos estos aspectos de la ciencia, así como para los relacionados con la ingeniería y los ingenios y la arquitectura remitimos a las ex-

18 El estudio más completo y actual sobre el nacimiento y evolución de la Academia de Matemáticas de Madrid puede encontrarse en el libro de María Isabel ViCENTE MAROTO y Mariano Esteban PiñeIro, Aspectos de la Ciencia Aplicada en la España del Siglo de Oro, Salamanca, Junta de Castilla y León, 1991, pp. 17-218. También podemos encontrar en esta obra un estudio detallado de los instrumentos de medida -astrolabios, planisferios, anillos astronómicos, cuadrantes de círculo- y sus bases teóricas. 
celentes estudios de Isabel Vicente Maroto, Mariano Estaban Piñeiro y Nicolás García Tapia ${ }^{19}$.

Otro de los aspectos técnicos y científicos que se desarrollaron en el siglo XVI fue el de la minería. En España existían importantes explotaciones mineras, como la de Almadén, de mercurio o azogue, pero el descubrimiento de las minas de plata americanas hizo que se buscara y se investigara la manera de extraer el mineral con mayor facilidad y menos costo. Los metales nobles eran fundamentales desde que el desarrollo del comercio requería, de forma creciente, la existencia de grandes reservas monetarias. De ahí que Portugal con Enrique el Navegante buscara el oro africano y España el americano. La explotación española de las minas se estableció desde un comienzo con un contrato entre el explotador y la corona, que cobraba un quinto del beneficio.

La extracción del metal solía hacerse en Europa, y después en América, por fundición, utilizando para ello hornos de leña. Así se fue acabando con la madera tanto en España como en América, hasta el punto que ya no se podía hacer el enconfrado de las minas con este material y hubo que hacer pilastros de cal y canto. Pero la cuestión se hizo más grave aún cuando se fueron agotando los minerales de alta ley y quedaron los de mediana o baja. Lo cierto es que todo el mundo buscaba métodos nuevos que permitieran mejor rendimiento. El descubridor de ese nuevo método que tanto se necesitaba fue Bartolomé de Medina, que se había relacionado con los mineros alemanes que trabajaban para los Fugger, quienes habían obtenido la concesión de las minas de Guadalcanal, siempre gracias a los empréstitos que hacían a la corona. Medina encontró un método de «amalgamación», pues el mercurio hace que se desprenda la plata del mineral en que se encuentra, formando una mezcla que así se llama, amalgama. Contaba el propio Medina en 1555 su descubri-

19 Las obras de García Tapia son fundamentales aportaciones para el conocimiento de la ingeniería, la arquitectura, y la variedad de invenciones que se dieron a lo largo del Siglo de Oro español: Nicolás GARCÍA TAPIA, Técnica y Poder en Castilla durante los siglos XVI y XVII , Salamanca, Junta de Castilla y León, 1989; Ingeniería y Arquitectura en el Renacimeinto Español, Valladolid, Secretariado de Publicaciones, Universidad de Valladolid, Caja Salamanca, 1990; Patentes de invención españolas en el Siglo de Oro, Madrid, Ministerio de Industria y Energía. Centro de Publicaciones, 1990; y de José Antonio García DIEGO Y Nicolás GARCía TAPIA, Vida y técnica en el Renacimiento. Manuscrito de Francisco Lobato, vecino de Medina del Campo, Valladolid, Secretariado de Publicaciones, Universidad de Valladolid, 1987. 
miento diciendo: «...tuve noticia en España, de pláticas con un alemán, que se podía sacar la plata de los metales sin fundición, ni afinaciones y sin grandes costas; y con esta noticia determiné venir a esta Nueva España a probarlo». Lo cierto es que el procedimiento, también llamado «beneficio de patio ${ }^{20}$ », se generalizó no sólo en América, sino también en Europa, aunque eso no quiere decir que la técnica de la fundición despareciera ${ }^{21}$. En el siglo XVII fue Álvaro Alonso Barba, con su Arte de los metales quien continuó con la difusión de las técnicas - llamadas artes porque en realidad no se conocía bien la técnica en cuanto a cantidades y procesos químicos- de la minería ${ }^{22}$.

Me referiré ahora a un aspecto del conocimiento que fue realmente llamativo durante el reinado de Felipe II, la naturaleza americana, que además de ser un estímulo para los relatos de viajeros, funcionarios, conquistadores y frailes fue también un estímulo para los intereses de la Corona. Cierto es que desde los primeros momentos del descubrimiento la Corona española se interesó, como es lógico, por las características de la naturaleza y de los hombres encontrados, haciendo preguntas sobre los diferentes aspectos de los territorios. A medida que pasaban los años las preguntas se iban organizando en cuestionarios cada vez más detallados y complejos, que tenían en cuenta los aspectos geográficos, demográficos, la fauna y la flora y los minerales. Fauna y flora eran importantes para la alimentación, la medicina, algunas industrias como la tintórea y el comercio en general. Toda esta actividad culminó en los años sesenta y setenta del siglo XVI con la visita y reorganización del Consejo de Indias, reorganización capitaneada por Juan de Ovando que tenía a su vera a Juan López de Velasco ${ }^{23}$, un gran conocedor, desde

20 Se hacían unas tortas con la amalgama que debían depositarse en grandes espacios o patios para que se fueran secando.

21 Sobre la minería pueden consultarse: Mervyn F. LANG, «Amalgamación y fundición en la minería americana», en J.L García HourCADE, J.M. MORENO y G. RuIZ HERNÁNDEZ, Estudios de Historia de las Técnicas, la Arqueología Industrial y las Ciencias, vol II, Salamanca, Junta de Castilla y León, 1998, pp. 671-677; Julio SÁNCHEZ, Minería y metalurgia en la Edad Moderna, Madrid, Akal, 1997.

22 Álvaro Alonso BARBA, Arte de los metales en que se enseña el verdadero beneficio de los metales de oro, y plata por azogue, el modo de fundirlos todos, y como se han de refinar, y apartar unos de otros, Madrid, Imp. Del Reyno, 1640. Hubo múltiples ediciones posteriores en castellano, inglés, alemán, francés e italiano.

23 Juan de Ovando y Godoy había nacido en Cáceres, fue canónigo en Sevilla y estuvo ligado a las actividades de la Universidad de Alcalá de Henares. En 1568, cuando el carde-

R. I., $1999, \mathrm{n}^{\circ} 215$ 
la península, de las cuestiones americanas. A lo largo del siglo XVI hubo figuras señeras en la descripción de la naturaleza americana, como Gonzalo Fernández de Oviedo, Bernardino de Sahagún, Francisco Hernández y José de Acosta.

Oviedo pertenece al período del Imperio de Carlos y del entusiasmo y la divulgación de los hallazgos sorprendentes. Su primera obra, redactada rápidamente y publicada en 1526 —el primer tratado sobre la naturaleza americana de Europa, casi un manual sobre la fauna, el Sumario de la natural historia de las Indias ${ }^{24}$ - en uno de sus viajes a la península, estaba dedicada al Emperador Carlos, y su siguiente trabajo, ya más completo, apareció en 1535, siendo sus escritos, además, divulgados por Ramusio en su Navegazioni et Via$g i^{25}$ y por Pedro Mártir en sus Décadas de Orbe Novo ${ }^{26}$. Oviedo realizaba unas detalladas y vivas descripciones, acompañadas de sus experiencias propias, dando una sensación fresca y directa. Su formación a la sombra de la Corte le había permitido, en la época de su estancia con el duque de Calabria, leer incluso a Plinio - según parece en toscano-, y en él se inspira. Pero era su curiosidad y capa-

nal Espinosa realiza la Junta y es llamado Ovando, éste era consejero de la Inquisición. Murió en 1575 , y fue López de Velasco quien continuó llevando adelante las actividades del Consejo de Indias. No se sabe bien la fecha de nacimiento de este interesante personaje, entre 1530 y 1540 dice M.C. GONZÁLEZ MUÑOZ en el «Estudio preliminar» a la edición de la obra de López de Velasco, pero sí que murió en Madrid en 1598. Tanto Juan de Ovando como Juan López de Velasco fueron figuras relevantes, y mucho, para la ciencia y la política de conocimiento del reinado de Felipe II.

24 Gonzalo FERNÁNDEZ DE OVIEDO, Sumario de la natural historia de las Indias, Edición de Manuel Ballesteros, Madrid, Historia16, 1986. Comprende, además de unos capítulos generales sobre la navegación, la isla Española, las costumbres de los indígenas, varios capítulos en que se ocupa de describir casi sesenta especies animales y casi viente vegetales, además de hablar de las minas de oro y las pesquerías de perlas. En total ochenta y seis capítulos. Su obra posterior, en diecinueve libros, se titulaba Historia General de las Indias, en diecinueve libros, publicada en 1535, en la que se comprendían los libros dedicados específicamente a los vegetales - libros VII a XI- y a los animales - libros XII a XVsiguiendo aproximadamente la metodología de Plinio. El libro XX se publicó posteriormente, y la obra completa - Historia General y Natural de las Indias, islas y Tierra-firme del mar Océano-, apareció en el siglo XIX, publicada por Amador de los Ríos en tres volúmenes en 1851-1855. Hoy existe una edición de Juan Pérez de Tudela Bueso publicada en Madrid, Ediciones Atlas, 1992, en cinco volúmenes.

25 Giovanni Battista RAMUSIO, Navigazioni et Viagi, vol. 3, 1556. El Sumario se encuentra entre los folios 44 y 74 y la Historia General entre los folios 74 y 224.

26 Se puede consultar la obra de José PARDo TOMÁs y María Luz LóPEZ TERRADA, Las Primeras noticias sobre plantas americanas en las Relaciones de Viajes y Crónicas de Indias (1493-1553), Valencia, CSIC, 1993. 
cidad de observación lo que permitía sus tan ricas y correctas descripciones, nada fáciles para una persona no dedicada a la historia natural ni a la medicina. Sus obras se difundieron bien, aunque la versión final y más amplia ya no alcanzó la publicación, que fue recogida en el siglo XIX por Amador de los Ríos.

Quizás el límite de esa alegre difusión de las noticias americanas se pueda establecer con la obra realizada en México, en el convento de Huaxtepec, sobre medicina mexicana. El llamado Códice CruzBadiano, porque fue redactado por un médico indígena aculturado, Martín de la Cruz, y traducido al latín por otro indígena, Juan Badiano, se titulaba Libellum de medicinalibus indorum herbis, y fue también realizado para y en honor del emperador Carlos, en 1554. Se redactó y obsequió en defensa del Colegio y convento de Huaxtepec, en el que se educaba a indígenas, y que estaba en estado de decadencia y a punto del cierre. Se quería demostrar la utilidad de la educación indígena con este libro de medicina, en que aparecían, ordenadas según la medicina galénica, productos medicinales indígenas, recetas para todas las enfermedades, ilustradas con hermosísimas láminas que representaban las plantas utilizadas. En 1556 sube Felipe II al trono. En la década de los sesenta y setenta Fray Bernardino de Sahagún reside en ese mismo convento, y su afán de conocer la lengua y las costumbres indígenas para buscar la forma más adecuada de evangelizarlos, le lleva a un trabajo ímprobo y excepcional. Elabora cuestionarios con preguntas, y va preguntando detalladamente a los indígenas el significado y el nombre de todos los aspectos de su vida y del entorno que les rodea. Su excelente trabajo, Historia general de las cosas de Nueva España ${ }^{27}$ uno de los más ricos que se conocen en este aspectos, fue reclamado por la Corona en los años sesenta, y una vez entregado por el fraile, se retuvo en manuscrito, no siendo publicado hasta los tiempos presentes. Lo mismo se puede decir de la labor del médico toledano Francisco Hernández, enviado por el rey Felipe II a estudiar la naturaleza americana, pero cuya obra de siete años no fue tampoco publicada por el rey, que la retuvo en El Escorial hasta su destrucción en un incendio del Monasterio en 1671. Tampoco se quería dar a luz la información

27 Bernardino de SAHAgún, Historia general de las cosas de Nueva España, 2 vols., Edición de Alfredo LóPEZ Austin y Josefina GARCíA QuiNTANA, Madrid, alianza Editorial, 1988. Comprende el texto completo de la parte en castellano del Códice Florentino.

R. I., $1999, \mathrm{n}^{\circ} 215$ 
recopilada por medio de los cuestionarios enviados en los años setenta y ochenta a los territorios de ultramar, como veremos más adelante. Las obras que se publicaron en esta segunda mitad del siglo XVI fueron, creo, menos significativas desde el punto de vista de informaciones especiales sobre la regiones americanas. El libro del jesuíta José de Acosta - Historia Natural y Moral de las Indias occidentales, 1590 - es interesante por sus reflexiones sobre la naturaleza americana y su relación con la creación, la existencia de especies americanas diferentes, de hombres diferentes, la posibilidad de vida en la zona tórrida, pero sin grandes especificaciones ni detalles sobre las zonas visitadas. No aportaba una información que pudiera ser políticamente peligrosa. Queremos decir con esto que, aunque Felipe II fue un gran impulsor del conocimiento científico de la naturaleza americana, fue quizás, por otro lado, y por razones políticas y religiosas e incluso económicas, un gran freno a un desarrollo posterior de las ciencias que nacían a la sombra del descubrimiento americano. Influyó en este proceso también, indudablemente, la situación económica ${ }^{28} \mathrm{y}$, quizás, los cambios demográficos que se producían en Castilla, y el hundimiento de muchas de sus ciuda$\operatorname{des}^{29}$, con la desaparición de una cierta clase que podríamos llamar «media», ciudadana ${ }^{30}$, que hubiera podido sustentar esos especialis-

28 John H. ElLIOTT, el Viejo Mundo y el Nuevo 1492-1650, Madrid, Alianza Editorial, 1984. Dice Elliott en las páginas 81-82: «Doce años antes de la famosa exposición de Bodin de 1568 sobre las causas de la elevación de los precios, el navarro Martín de Azpilicueta, perteneciente a la escuela de Salamanca, había puesto en relación de una forma clara el elevado coste de la vida en España con la afluencia de la plata americana. Ya habían pasado viente años desde que Fernández de Oviedo había escrito que España era una de las más ricas provincias del mundo y que Dios le había conferido la gracia especial de las riquezas adicionales de las Indias. Cuando Oviedo escribió estas palabras, la economía castellana estaba disfrutando de los beneficios de un creciente comercio a través del Atlántico. Pero cuando lo hizo Azpilicueta, la situación económica estaba empezando a cambiar. Los precios de los productos castellanos estaban aumentando más rápidamente que los de los otros países, y la balanza comercial de Castilla con otros países de Europa era más desfavorable, ya que importaba más productos de los que exportaba y tenía que cubrir el déficit con la plata americana». Sabemos, además, los extraordinarios gastos que implicaban todos los frentes de guerra abiertos durante el reinado de Felipe II.

29 Creo especialmente interesante, para intentar comprender el proceso de decadencia que sufrió Castilla, el trabajo de Bartolomé Yun Casalilla, «Poder y economía. Algunas propuestas para el estudio dde la historia agraria de Castilla la Vieja y León durante la Edad Moderna», en Relaciones de poder, producción y parentesco en la Edad Media y Moderna, Reyna PASTOR, Compiladora, Madrid, CSIC, 1990, pp. 375-409.

30 Sobre las clase sociales de la Península es interesante leer el libro de Ruth PIKE, Aristócratas y comerciantes, Madrid, Ariel, 1978, y también el de Bartolomé BENNASSAR, 
tas y estudiosos que, a su vez, podían haber promovido una institucionalización de la ciencia que no se dio en las décadas siguientes. López Piñero dice que en los años 1557-59 se produjo una crisis de comunicación con los otros países europeos, y demuestra que hay un retroceso en el número de publicaciones científicas ${ }^{31}$.

Pero la organización por la Corona de una forma de conocer la realidad americana y su naturaleza fue realmente significativa y sorprendente en su momento, dando lugar a una importantísima recopilación de conocimientos, conocimientos que, según se ha visto con el tiempo, no se querían divulgar más que limitadamente. Con Felipe II se inaugura una época de especial control de toda información sobre los dominios americanos, aunque al mismo tiempo la Corona quiera saber todo lo posible sobre ellos. Y ese saber se concreta en el final de la década de los años sesenta y en la de los setenta. El Consejo de Indias tenía un verdadero caos legal con respecto a la leyes, instrucciones y documentos varios sobre las Indias. Desde comienzos de los años sesenta se intentaba recopilar toda esa documentación. Por otra parte, muchos informantes venidos de Indias hablaban de la situación bastante descontrolada que allí se vivía, con una extremada explotación de la población indígena y una deficiente explotación de los productos naturales, y se acusaba a las autoridades de la Península de un absoluto desconocimiento de los territorios americanos y de lo que allí sucedía. Se produjeron crisis políticas en los virreiantos del Perú y México, con rebeliones de los españoles, conquistadores o sus descendientes. Todo ello condujo a que se tratara del asunto en una Junta Extraordinaria en 1568, y a que el en ese momento poderoso cardenal Espinosa nombrara a un hombre de confianza, también procedente de la Inquisición, para que realizara una Visita o inspección del Consejo de Indias. El Visitador fue Juan de Ovando, que hizo una excelente limpieza y recopilación de las

La España del Siglo de Oro, Barcelona, 1983, especialmente los capítulos 8 y 9. Y en relación con la ciencia sigue siendo imprescindible el libro de José María LÓPEZ PIÑERO, Ciencia y Técnica en la Sociedad Española de los Siglos XVI y XVII, Barcelona, Editorial Labor, 1979, en especial, en este aspecto, el Capítulo II, «Posición social de los cultivadores de la ciencia», pp. 47-88.

31 LÓPEZ PIÑERO, [28], pp. 140-148. Se refiere aquí a la pragmática de 1558, que restringía la venta de libros extranjeros y a la prohibición de 1559 de «pasar los naturales de estos reinos a estudiar a universidades fuera de ellos» y recuerda los índices de libros prohibidos preparados por los inquisidores Fernando de Valdés (1559), y Gaspar de Quiroga (1583 y 1584).

R. I., $1999, \mathrm{n}^{\circ} 215$ 
leyes de Indias. Junto a él, Juan López de Velasco, buen conocedor de las interioridades del Consejo, con conocimientos de cosmografía y geografía y que fue nombrado en 1571 primer CosmógrafoCronista del Consejo de Indias.

La obra que López de Velasco presentó por razón de su cargo, Geografía y Descripción Universal de las Indias ${ }^{32}$, breve pero buscando referirse a todos los puntos interesante referentes a América, esencialmente la geografía y más que nada los límites de las tierras americanas que pertenecían a la corona - la «Demarcación de los Reyes de Castilla»- demuestra la información que se poseía en el Consejo en esos momentos y la documentación que López de Velasco manejaba, pues recordemos que había recibido todos los papeles del cosmógrafo Alonso de Santa Cruz. Aunque el libro de López de Velasco no fue publicado hasta 1582 - había sido presentado al Consejo en 1574 - y fue muy criticado por el cosmógrafo Juan Bautista Gessio por - según él - la poca exactitud de sus coordenadas geográficas, hay que decir que contiene reflexiones muy interesantes. Cuando se refiere a «La primera población de las Indias» analiza las diferentes opiniones y posibilidades que se habían planteado sobre el asunto: la posible existencia de unas tierras que ocupaban el Atlántico, como escribía Platón en el Timeo - diálogo esencial del filósofo en cuanto a su influencia en la ontología de los siglos posteriores- diciendo «no se tiene por historia auténtica, no consta que Platón en el dicho diálogo quiere que lo sea, ni tampoco cuadra a la orden y constitución del Universo, que una tan grande parte de él pereciese y se viniese a anegar ${ }^{33} \gg$; las posibles navegaciones de cartagineses o de Salomón a las islas de Ofir y Tarsis; y una de las hipótesis más manejada, la de la peregrinación de las diez tribus de Israel ${ }^{34}$, concluyendo el autor que «todas son conjeturas flacas». Y señala:

«Y así sólo queda por creer, hasta que haya mayor averiguación, que aquel Nuevo Mundo se junta con estotro por alguna parte, como de

32 Juan LÓPEZ DE VELASCO, Geografía y Descripción Universal de las Indias, Edición de Marcos JIMÉNEZ DE LA ESPADA con estudio preliminar de María del Carmen GoNZÁLEZ MuÑOZ, Madrid, Atlas, 1971.

33 LÓPEZ DE VELASCO, nota 29, p. 2.

34 El problema era que la Creación era una, y no se podía admitir que Dios hubiera creado a unos hombres en un sitio y a los pobladores de América en otro. Tenían que haber llegado desde el núcleo de la creación en el Cercano Oriente. 
ello da indicio la costa de la China y de la Nueva España, que van corriendo en viaje de juntarse por la parte del septentrión; y que siendo así, se habrán por aquella parte dilatado en tantos siglos poco a poco las gentes hasta llegar donde ahora están, y cuando esto no sea, será posible en los años del mundo haber llegado de otras partes dél, vecinos, a aquellas, gentes navegando o derrotadas, como de Irlanda y de las partes septentrionales se navega a los Bacallaos, de donde se comenzase a poblar aquel Nuevo Mundo; aunque lo más verosímil parece estar continuados estos dos mundos, o haberlo estado aunque ahora no lo estén, y que por alguna parte podría el mar haber rompido y hecho algún estrecho por donde, antes que se hiciese, hayan pasado los hombres y los leones, tigres, dantas y venados, y otros animales de estas partes, que se hallan en aquellas, que no parece pudieron haber pasado de otra manera ${ }^{35}{ }_{\text {» }}$

El jesuíta José de Acosta, defendía la misma idea en su libro Historia natural y moral de las Indias, publicado por primera vez en Sevilla en 1590 y que tuvo gran difusión europea. Acosta elabora su argumentación por medio de razonamientos religiosos. Ha sido muy alabado por su «genial intuición» con respecto a la continuidad del paso por el norte, pero hemos visto que ya en 1574 López de Velasco decía lo mismo, y es probable que fuera una idea bastante generalizada por aquellos tiempos, quizás porque coincidían las argumentaciones científicas y religiosas. Decía Acosta:

«La razón porque nos hallamos forzados a decir que los hombres de las Indias fueron de Europa o de Asia, es por no contradecir a la Sagrada Escritura, que claramente enseña que todos los hombres descienden de Adán, y así no podemos dar otro origen a los hombres de Indias, pues la misma Divina Escritura también nos dice que todas las bestias y animales de la tierra perecieron, sino las que se reservaron en el Arca de Noé, así también es fuerza reducir la propagación de todos los animales dichos, a los que salieron del arca en el monte de Ararat, donde ella hizo pie; de manera que como para los hombres, así también para las bestias nos es necesidad buscar camino por donde hayan pasado del Viejo Mundo al Nuevo ${ }^{36}{ }_{»}$.

Después de analizar largamente la opinión de San Agustín y lo que dice la escritura y también las posibilidades que los animales

35 LÓPEZ DE VELASCO, [29], p. 2. Las cursivas son mías.

36 José de Acosta, Historia Natural y Moral de las Indias, edición de José AlcinA FRANCH, Madrid, Historia 16, 1987, p 111. El texto se refiere al Génesis, 7, 21, 22, 23.

\section{R. I., $1999, \mathrm{n}^{\circ} 215$}


pudieran cruzar el océano, así como el conocimiento que se tenía de que las tierras se extendían hacia el norte sin saber dónde tenían fin. Por todo ellos concluye:

«Así que ni hay razón en contrario, ni experiencia que deshaga mi imaginación u opinión, de que toda la tierra se junta y continúa en alguna parte; a lo menos se allega mucho. Si esto es verdad como en efecto me lo parece, fácil respuesta tiene la duda tan difícil que habíamos propuesto, cómo pasaron a las Indias los primeros pobladores de ellas, porque se ha de decir que pasaron no tanto navegando por mar como caminando por tierra. Y ese camino lo hicieron muy sin pensar mudando sitios y tierras su poco poco, y unos poblando las ya halladas, otros buscando otras de nuevo, vinieron por discurso de tiempo a henchir las tierras de Indias de tantas naciones gentes y lenguas ${ }^{37} \gg$.

Por otra parte, si Ovando fue el gran organizador de un Código que buscaba ordenar las leyes de Indias, inlcuyendo el conocimiento de las tierras conquistadas, con el documento titulado «La forma que se había de tener en hacer las averiguaciones, descripciones y rela-

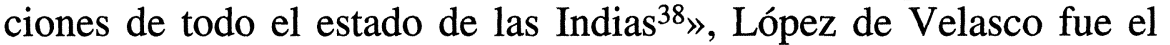
creador de las formas concretas de recogida de información americana -y posiblemente también de la española, con la «Relaciones Topográficas de España»- estructurando excelentes cuestionarios para recoger y organizar los datos. Una serie de respuestas organizadas sistemáticamente dan pie a reconstruir un cuestionario de doscientas preguntas ${ }^{39}$ que abarcaba todo tipo de conocimientos geográficos, demográficos, sobre la naturaleza vegetal y animal, etc., y que seguramente debía utilizarse en el propio Consejo, haciendo las preguntas a quienes venían de ultramar. También se realizaron múlti-

37 ACosta, [33], pp.113-114.

38 Las Ordenanzas que elaboraba Ovando eran aprobadas muy lentamente por Felipe II. Este «Título de las Descripciones» fue aprobada en 1573, después de casi dos años de espera. Sobre el contenido del documento, consultar de Pilar PONCE, «Las Ordenanzas sobre Descripciones (1573). Su aplicación en la Real Audiencia de Quito», en Franciso SOlANO editor, Cuestionarios para la formación de las Relaciones Geográficas de Indias. Siglos XVI/XIX, Madrid, CSIC, 1988, pp. LXXIX-XCI.

39 Sobre este cuestionario y su evolución, consultar Raquel Álvarez PelÁEZ, La conquista de la naturaleza americana, Madrid, CSIC, 1995; y sobre los cuestionarios que se enviaron a Indias en 1577, Raquel ÁlVAREZ PELÁEZ, «El cuestionario de 1577. La «Instrucción y Memoria de las Relaciones que se han de hacer para la Descripción de las Indias"», en SOLANO, editor, [35], pp. XCIII-CVI. 
ples cuestionarios sobre cuestiones económicas, militares, religiosas. Pero el conocimiento de la naturaleza y de todos los aspectos geográficos y corográficos de América debían de considerarse realmente importantes, porque en esos mismos años setenta, y probablemente por idea de Juan de Ovando, se decide enviar a un estudioso, un médico especialmente preparado no sólo para la práctica de la profesión, sino experto en el conocimiento de plantas y animales, para que realizara un estudio de la naturaleza americana y fundamentalmente de los productos medicinales, que en principio se quería que fuera de los dos grandes virreinatos, Perú y Nueva España, y que por la intensidad y extensión de la tarea sólo pudo hacerse de Nueva España. Se eligió para la tarea al médico toledano Francisco Hernández, amigo de Juan de Ovando y de Benito Arias Montano, bien preparado en Alcalá de Henares, que había herborizado por la zona de Sevilla y por Guadalupe, donde además del jardín de Plantas Medicinales también se disecaban animales. Además se enviaba a un cosmógrafo, Francisco Domínguez, para levantar un mapa de la Nueva España, pero su labor no fue nunca impresa y se perdió, aunque Hernández a su vuelta trajo la «corografía de México» que seguramente pereció en el incendio del Escorial junto con el resto de materiales del toledano. Además, a partir de ese cuestionario de doscientas preguntas, concentrándolo, se elabora uno de cincuenta preguntas que fue enviado a todos los rincones de las posesiones españolas para que los funcionarios locales lo completaran. El contenido comprendía datos geográficos - ríos, lagos, montañas, etc. - situación de ciudades y pueblos, caminos, producciones alimenticias, materiales de construcción, animales, plantas, poblaciones, sus ritos y costumbres y su historia, existencia de iglesias, hospitales, etc, y existencia o no de puertos y sus características ${ }^{40}$. Estos cuestionarios, enviado primero en 1577 - año en que regresó Francisco Hernández de México - y también en 1584, recibió gran número de respuestas, fundamentalmente de la Nueva España, aunque no sabemos el número exacto porque muchas se perdieron. Conocemos ciento sesenta y siete de Nueva España, doce de la gobernación de Venezuela, siete del Nuevo Reino de Granada, una del Caribe, quince del Perú y diez de la Audiencia de Quito. Es un gran cuerpo do-

40 Puede encontrarse el cuestionario reproducido en Álvarez PELÁEZ, [37], pp. 597607, y un análisis del contenido en las pp.185-215.

R. I., $1999, \mathrm{n}^{\circ} 215$ 
cumental con muy interesantes contenidos útiles tanto para la historia de la ciencia - plantas medicinales, aplicación de la medicina, animales, determinaciones geográficas, etc.- como para la historia en general. Transmiten, en muchas ocasiones, no siempre, vivencias interesantes que nos permiten entrever, de alguna manera, muchas de las formas de vida de aquellos años ${ }^{41}$.

La labor de Francisco Hernández, que se realizó entre 1570 y 1577 fue específicamente científica, como lo manifiesta claramente, tanto su elección, como las instrucciones que llevaba y, evidentemente, el resultado de su actividad, una gran Historia Natural que no llegó nunca a ser publicada tal como Hernández la redactó, ni como él hubiera querido ${ }^{42}$. Las peripecias de los escritos y maravillosas láminas de factura indígena de plantas y animales que trajo Hernández de Nueva España ya se han relatado en varios trabajos, que hemos citado más arriba. Sólo diremos que el trabajo de Hernández despertó gran expectación en Europa, pues los estudiosos de todos los países estaban interesados en la fauna y flora americanas ${ }^{43}$, y por esta razón el manuscrito que Felipe II hizo preparar a su destilador y médico Nardo Antonio Recchi a partir de la Historia Natural de Hernández - un manual de plantas medicinales americanas- fue ansiosamente buscado y después publicado, en el siglo XVII, por la italiana Accademia dei Lincei, como puede leerse en el libro ya citado, De materia Medica Novae Hispaniae. Manuscrito de Recchi, -el texto de ese manual de plantas medicinales-y en otros muchos

41 En Álvarez PeláEZ, [37], puede encontrarse un estudio sobre los contenidos de la Relaciones sobre historia natural y medicina, pp. 233-525.

42 Sobre Francisco Hernández, su biografía, su expedición americana, sus trabajos y su historia natural, pueden consultarse las Obras Completas, México, UNAM, 7 volúmenes, 1960 , así como los capítulos correspondientes de Álvarez PELÁEZ, 37, pp. 99-124, y de Álvarez PelÁEZ, «Estudio Introductorio» en De Materia Medica Novae Hispaniae. Manuscrito de Recchi, Aranjuez, Ediciones Doce Calles, 1998, pp. 21-138.

43 En la correspondencia de la Accademia dei Lincei puede verse cómo G. della Porta, Ulysse Aldrovandi, Ferrante Imperato, Fabio Colonna y, claro está, los editores de la obra Rerum medicarum Novae Hispaniae thesaurus, (Roma 1651), Federico Cesi, Johannes Faber, Stelluti, Terrenzio, y también Galileo, él también miembro de los Lincei, se ocuparon y preocuparon por la existencia, primero de los escritos de Hernández y después por el manuscrito de Recchi. Los Lincei construyeron toda una gran obra de historia natural en torno a este manuscrito, agregando glosas de las descripciones de Hernández, libros de comentarios sobre los animales y las plantas y una tablas «fitosóficas» del propio Cesi como esquema de la organización de la naturaleza. La correspondencia completa puede verse en Giuseppe Gabrieli, Carteggio Linceo, Roma, Accademia dei Lincei, 1996 y la historia de la edición del manuscrito en Álvarez PeláEZ, [40], pp. 70-101. 
textos cuya bibliografía puede encontrarse en ese mismo texto. Desgraciadamente, pues, cuando Hrnández regresa cargado con sus volúmenes, semillas y plantas, el rey no le hace caso, le acusan de gastos excesivos y no le permiten preparar la obra para publicar, sino que, como hemos dicho, se la dan a alguien que no conocía América para hacer un manual o resumen medicinal.

Como hemos dicho, pues, en el reinado de Felipe II se desarrolló la ciencia en varios de sus aspectos, aunque ese despertar provenía de tiempos anteriores, del espíritu humanista y renacentista que venía desde finales del XV y principios del XVI y adquirió auge, con el erasmismo y el contaco con el resto de las naciones europeas a lo largo de la primera mitad del siglo. Después, aunque este ímpetu científico despertado por ese nuevo espíritu y el descubrimeinto de América se mantuvo y se incrementó en una serie de aspectos que hemos señalado, también es cierto que la crisis religiosa, los problemas económicos y los cambios sociales fueron creando dificultades en la progresión y desenvolvimiento de la ciencia, sin que se viera un proceso de institucionalización, ni la formación de escuelas a partir de los brillantes estudiosos, y el panorama de nuestra ciencia a lo largo del siglo XVII - las fechas son siempre inexactas, son sólo para entendernos - no alcanzó el nivel que fue adquiriendo en otros países europeos.

During the XVIth Century the Spanish science reached a great development, especially in some fields like that of navigation, mining, natural history, etc. The discovery of the New World was an essential factor in the impulse of that scientific development, that favored and stimulated by Felipe II, was bindered also during their reign, in great measure due to the burden religious, economic and political problems that thought about in those years. 